\title{
Construction of Industrial Strategy Model Based on the Multi-Agent
}

\author{
Zhu Yadong
}

School of Economics and Management, Hebei University of Technology,Tianjin,P.R.China, 300401

Email: zydchina@139.com

Keywords: Industrial strategy; multi-agent; model

\begin{abstract}
In this paper, considering the complexity of the industrial strategy and uncertainty of the environment, Multi-agent system based on intelligent agent is put forward, and the model to be used in industrial strategic management and group decision support system is constructed.
\end{abstract}

\section{Introduction}

During these years, the theory of enterprise strategy has entered into a mature stage, and has a rich theoretical basis. Contrasted with the enterprise strategy management, the industrial strategy management, which is introduced by Michael Potter using industrial organization theory in the competition theory, is still in the initial stage. Relative researches have recently started, theoretical research is still lacking, and the research tool and utility model are not enough. Thus, in this paper, against this background, the strategic management and the overall framework model is put forward by using the Multi-agent modeling and control theory.

\section{Industry strategic management and group decision system framework}

With economic globalization deepening and the rapid development of science and technology, the long-term survival and development environment of the industry and enterprise is becoming more and more complicated. Thus, when establishing industrial and enterprise strategies, more decision-making information and decision-making methods are needed. As for the industry strategy, the factors concerning the global economy, the present situation of the development of the industry, the competition of the industry market should be considered when the relevant state departments (the government), industry associations, and industrial technology innovation alliance, industrial development research experts participate in the decision-making process of the strategy. For the enterprise strategy, it needs more parties to take part in its decision-making process, parties including technology, management, marketing, sales and financial personnel in the enterprise, and Experts specializing in different fields or consulting agencies. During the making process of the industry strategy, enterprises competitive strategy which will affect the development of it should be taken into account. Thus, the applicable, effective and reasonable industry and enterprise strategy can be made. During the strategic decision process, information platforms between industries and enterprises should be built up to make them communicate more quickly and conveniently for the sake of the intelligent decisions.

The overall structures between industry and enterprise strategic decisions are build up based on the relationship between the industry and enterprise and different participants, as is shown in figure 1. 


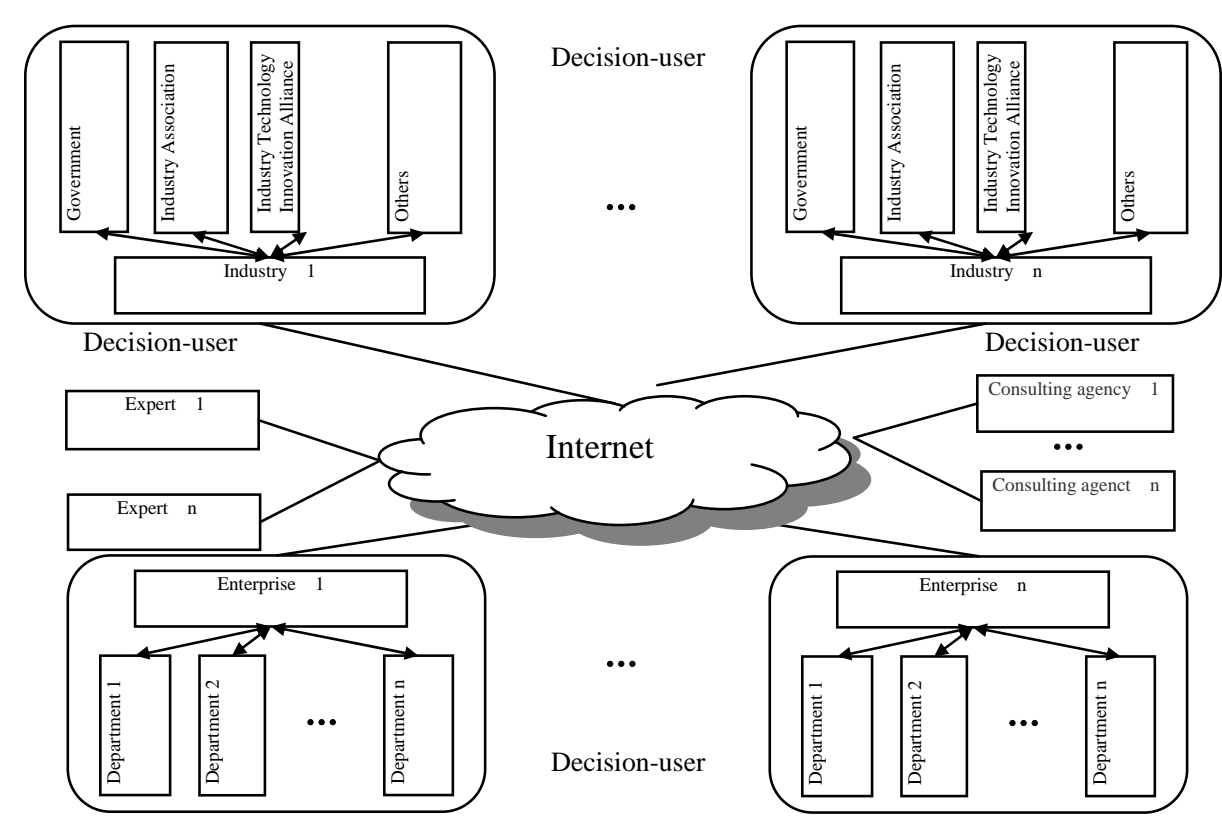

Figure 1 The general structure diagram of the industry strategic management and group decision system

\section{Structures of the Industry strategic management}

When devising industrial strategy, the following layers should be considered: Industry missions and strategic targets, Industrial environment analysis, the assessment and choice of the strategy, the implementation and control of the Industry strategy, as is shown in figure 2.

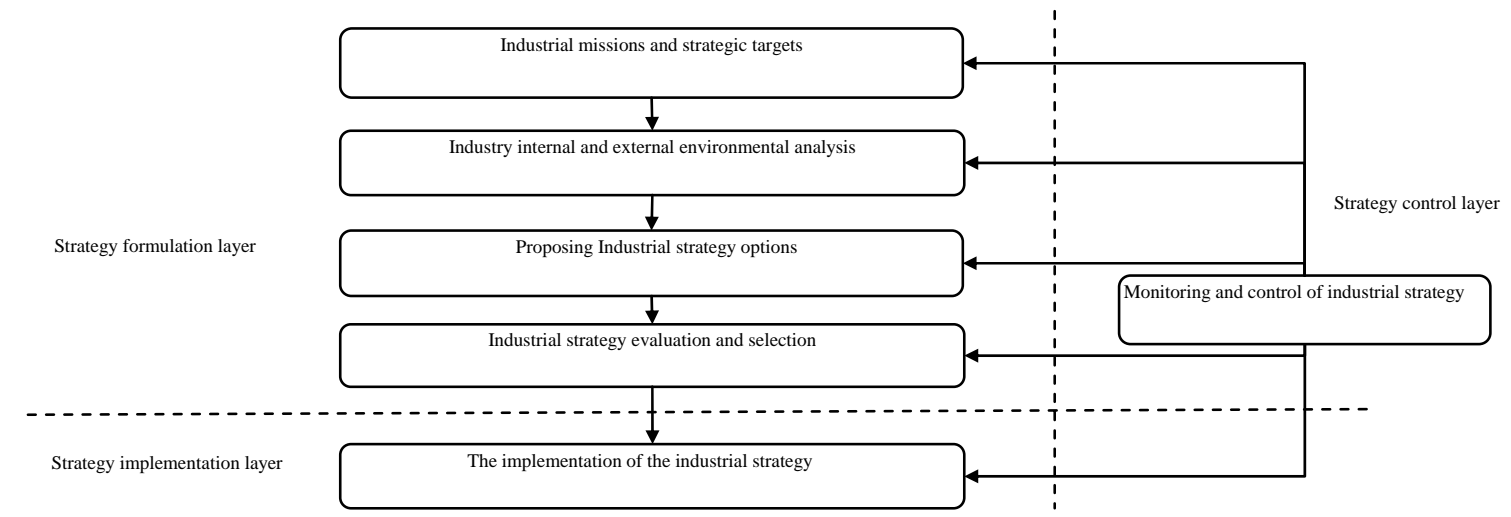

Figure 2 Process of the Industry Strategy Management

The main tasks to each layer are as follows:

Industry missions and strategic targets layer: the industry development planning and goal is set up mainly based on the Central Government planning and macroscopic goals in our national development.

Industrial environment analysis layer: the industrial internal and external environment is analyzed from the following aspects:

(1) Analysis of the industry economic policy. This mainly analyzes the macro economic situation, including the international economic situation, the domestic industry environment condition, and current development of the enterprise, and forecasts the influence of future trend, industrial policy, and economic laws over industrial strategy.

(2) The industrial development mission analysis is an important link to set up the industrial development target. And by analyzing the industrial development trend and the national economic situation, we can work out a long-term mission for the industry. By so doing we can come up with an according industrial strategy that is in line with the mission. 
(3) National competitiveness analysis. The biggest difference between the industry strategy and enterprise strategy is that the industry strategy attaches more importance to competition among countries. The industry's national competitiveness can be analyzed by gaining insight into national savings and investment capacity, industrial foundation and technical level, foreign competitors, more widely potential entrants, possible alternatives and enterprise strategic decision, etc.

(4) The competitiveness of the industry. It mainly analyzes industrial production and growth rate, production concentration. By analyzing trade competitive index, international market share, domestic market share and export product quality indices, the industry international competitiveness level can be best understood on a quantitative study, thus thrust some light upon growth curve of the industrial international competitiveness.

(5) Risk assessment analysis. It mainly analyzes potential field and its risk in the development, industry overall yield and growth rate, the effect of concentration after adjusting the industrial structure.

(6) Analysis of the industrial operation capability. It mainly analyzes the industry production, industrial competitiveness, industrial development, industrial technology ability and development ability, and whether the development of the enterprise conforms to the industry strategic planning.

(7) Analysis of the industry structure. It mainly analyzes quantity and distribution of enterprises in the industry, the competition status of enterprises, industry cycle, the industrial concentration, etc.

(8) Analysis of the Industry associations. It mainly analyzes the mutual contact, influence, the supply and demand relationship with the other industries.

(9) Analysis of the industrial organization. It mainly analyzes the form and relations of the enterprises in the industry, resource utilization and production efficiency in the industry.

(10) Industry attractiveness analysis.

The (7) - (10) can be combined into the industry and competitive analysis

Choice and evaluation of the Industry strategy: based on model library and rules of the industry strategy, strategy alternatives of the industry development can be worked out. Strategic feasibility, applicability, profitability and risks of the strategy can be assessed with the standards, and ultimately the best industrial development strategy can be selected.

Industry strategy implementation: each enterprise, including the relevant government department, industry management department, industry alliance, and associations, should formulate the implementation strategy or sub- strategy according to the industrial development strategy, which should be realized by using rational humans, capital, and equipment resources.

Strategic control: scanning, monitoring the industry internal and external environment, monitoring the effects and various problems in the implementation process, timely feedback to the industry strategic stakeholders in order to solve the problem of all levels, or to adjust industrial strategy duly.

\section{Industry strategic management and group decision Multi-agent system model}

Due to many environmental factors complicated and full of uncertainty in the strategic decisions, correlation of environmental factors, many decision-making mechanism participating in, the strategic decision-making system solid agents can be divided into more parts according to the industry, and then the industry agents is divided into more function agents according to the strategic decision function. The function agents include user Agent (the government management Agent, industrial association Agent, industrial union Agent, enterprise Agent, expert consultation Agent, etc.), and sub-function Agent (strategic control Agent, industry management department Agent in the government subordination, etc.).

In addition, the national government must build the information sharing platform to be used in the strategic management environment, which can provide all kinds of environmental information and data for each industry strategic management. The platform should rely on many environmental analysis Agents (including many environmental factor analysis Agents). 
On the basis of the above analysis, the decision-making system model based on Multi-agent industry strategy is structured, as shown in figure 3.

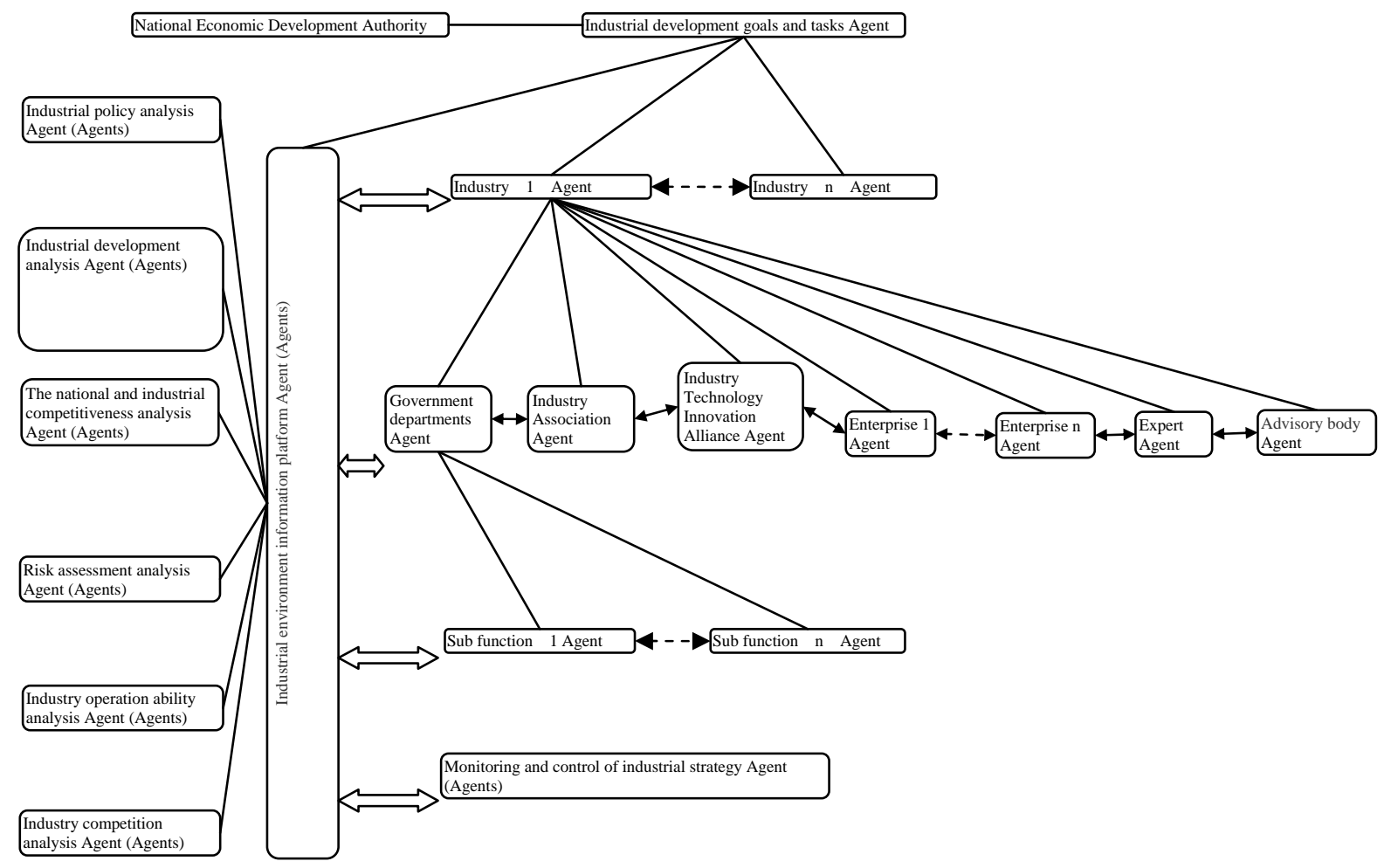

Figure 3 Framework structures of the group decision system model used in the Industry strategies The Model framework is based on the external access way. In the Model, departments, such as the management departments, decision-making groups, coordination departments, have different Agents groups with many functions, and the Agents groups interact. Thus, it will facilitate the co-sharing communication in the decision information, and be helpful in developing the industry and enterprise strategic decisions which would be more suitable for their common development.

The model internal detailed structure and principle are omitted here, which can be referred to in the related theory technical information.

\section{Conclusion}

Combining the Multi-agent group decision theory and the characteristics of the industry and enterprise strategies, the system model is put forth, which can be used in the industry and enterprise strategies. By using it, the decision makers can acquire the strategic decision-making information conveniently and fast, and more experts and related consulting units can take part in the decision-makings, which would be more reliable. At the same time, by using industry and enterprise strategic management together, the industry and enterprise strategic decision interact with each other, which will be helpful in the coordinative and collaborative development of industry and enterprise strategies.

\section{References}

[1] Ni Jianjun. Theory and Applications of Complex Systems Modeling and Control Based on Multi-agent[M]. Beijing, Publishing House of Electronics Industry, 2011

[2] He Yanxiang, Chen Xinmeng. Design and Application of Agent and Multi-Agent Systems[M]. Wuhan, Wuhan University Press, 2001 
[3] Michael E.Porter. The Competitive Advantage of Nations[M]. Beijing, CHINA CITIC PRESS, 2007

[4] Zhang Dongsheng, Li Yanshuang. Enterprise Strategy Management[M]. Beijing, China Machine Press, 2005

[5] Xu Xuanhua, Chen Xiaohong. Research of Model Administrate of DSS Based on Muti-agent[J]. Computer Engineering and Design, 2005,(13),pp.194-196

[6] Wang Shiqing, Li Chubing. Multi-Agent-Based supply chain model and simulatin[J]. Computer Engineering and Design, 2010, 31(5), pp.1081-1084

[7] Li Chunmei, Zou Ping. Design the Overall Framework of Enterprise Management Strategy GDSS Based Multi-Agent[J]. Systems Engineering-theory \& Practice, 2002, 22(5), pp.55-59.

[8] Yang Sibo, Li Minqiang. An Intelligent Control and Decision Making Model Based on Self-Organizing Multi-Agent System[J]. Journal of Tianjin University, 2012, 45(10),pp.904-911

[9] Sun Yongyong. Design of multi-Agent intelligent decision support system based on blackboard[J].Electronic Design Engineering, 2012, 20(16), pp.14-16

[10] Wooldridge M, Jennings N R. Intelligent agents: Theory and Practise[J]. Knowledge Engineering Review, 10(2) (1995)115-152

[11] R.Bose. Intelligent Agents Framework for Developing Knowledge-based Decision Support Systems for Collaborative Organizational Process[J]. Expert Systems with applications, 11,pp. 247-261,2006. 